\title{
Drug-related admissions and hospital-acquired adverse drug events in Germany: a longitudinal analysis from 2003 to 2007 of ICD-10-coded routine data
}

\author{
Jürgen Stausberg ${ }^{*}$ and Joerg Hasford
}

\begin{abstract}
Background: Adverse reactions and medication errors are complications of drug use. Spontaneous reporting systems and pharmacoepidemiological studies incompletely detect the occurrence of these events in daily hospital care. In this study, the frequency and type of drug-related admissions and hospital-acquired adverse drug events (ADE) in Germany were assessed using routinely collected hospital data.

Methods: The study was based on aggregated hospital routine data covering the period 2003 to 2007 and annually recorded as part of the further development of the German Diagnosis-Related Groups. The 505 ICD-10codes indicating an ADE were categorized in seven groups according to their certainty. Primary diagnoses were considered as a proxy for drug-related admissions, and secondary diagnoses as a proxy for hospital-acquired ADE.

Results: Among all hospital admissions, $5 \%$ were found to be at least possibly drug-induced and $0.7 \%$ very likely drug-induced. There was a significant increase in the overall rate of drug-related admissions over time $(p<0.038)$. Enterocolitis due to Clostridium difficile infection was the most frequent cause of a drug-related admission. About $4.5 \%$ of in-patients had experienced a hospital-acquired ADE. In addition, over the course of the study period, the overall frequency of hospital-acquired ADEs significantly increased $(p<0.001)$.

Conclusions: In Germany, more than 5\% of hospital episodes are either caused or complicated by an ADE. Between 2003 and 2007, there was a statistically significant increase in the overall rate and in some of the subcategories defined by the list of ICD-10-codes suspected to be indicative of an ADE. Before the use of routine data in pharmacovigilance and patient safety can be fully exploited, a further tailoring of both the ICD and the available variable set is needed.
\end{abstract}

\section{Background}

Adverse drug events (ADE) occur as a consequence of medication errors or as adverse drug reactions (ADR). Studies and systematic reviews have revealed that $5-10 \%$ of all internal-medicine admissions result from ADRs. Moreover, 5-10\% of all in-patients are expected to suffer from severe ADRs, and ADRs rate among the leading causes of death in the Western world [1-6]. However, $30-40 \%$ of those ADR are considered to be preventable

\footnotetext{
* Correspondence: juergen.stausberg@ibe.med.uni-muenchen.de Institut für Medizinische Informationsverarbeitung, Biometrie und Epidemiologie (IBE), Ludwig-Maximilians-Universität München, Marchioninistraße 15, D-81377 München, Germany
}

[3,7]. A report by the US American Institute of Medicine, "To Err Is Human: Building a Safer Health System," together with other, similar international reports, has had a lasting effect on public awareness with regard to safe pharmacotherapy and the prevention of medication errors [8]. In addition, as a result of these publications, critical-incident reporting systems and computerized physician-order entry systems combining patient- and medication-related information were recommended and subsequently introduced as a key approach to the reduction of medication errors [9-11].

With respect to ADRs, a variety of monitoring systems have been developed, the oldest and most common one

C Biomed Central

(c) 2011 Stausberg and Hasford; licensee BioMed Central Ltd. This is an Open Access article distributed under the terms of the Creative Commons Attribution License (http://creativecommons.org/licenses/by/2.0), which permits unrestricted use, distribution, and reproduction in any medium, provided the original work is properly cited. 
being the spontaneous reporting system [12]. In addition, there have been ad hoc epidemiological studies such as cohort and case-control studies whose aim was to elucidate the etiology of adverse events. Furthermore, the use of databases from health insurances and health care providers is very common in North America, the UK and Scandinavian countries where, compared to Germany, data confidentiality laws are less restrictive [13-15]. The traditional monitoring systems lack either in completeness due to an unsystematic approach [16] or lack in representativity due to a selective study design (cf. $[17,18]$ as examples for studies in single hospitals). By contrast, routinely collected reimbursement data promise both, completeness and representativity, through the coverage of nearly the whole population [19]. However, routinely collected reimbursement data have only rarely been evaluated for their suitability in pharmacovigilance and, especially, in the assessment of the ADEs of in- and out-patients in England and the United States [20-23]. Nonetheless, as the results of those few studies were in part encouraging, we decided to analyze the suitability of such databases in Germany.

In a recent report focusing on data from 2006, we showed that routinely collected hospital reimbursement data can be used to identify the frequency and type of ADE [24]. The present study explores this innovative approach in a nearly complete longitudinal sample of all in-patients. Specifically, we used this database to examine the frequency of drug-related admissions in Germany and of hospital-acquired ADEs during the years 2003 to 2007.

\section{Methods \\ Definition}

An ADE was defined as an injury resulting from a medical intervention related to a drug and thus included medication errors and ADRs [25-27]. Since a clear differentiation between ADRs and medication errors was not possible based on the available routine data; both events were subsumed within the definition of an ADE. Therefore, we refer to an ADR only if this term was used in the literature, even though the literature does not always provide a clear definition of an ADR.

\section{Database}

German hospitals are obliged to annually deliver a standard data set to the Institute for the Hospital Remuneration System (InEK). The data consist of information on all in-patients who are evaluated according to the system of diagnosis-related groups (DRG); thus, data from psychiatric and psychotherapeutic departments are excluded. The InEK uses the collected data for further development of the German DRG system (G-DRG). The hospital routine data comprise, among other items, diagnoses coded by the International Statistical Classification of Diseases and Related Health Problems, 10th Revision, German Modification (ICD-10-GM) and procedures coded according to a national classification of operations and procedures (OPS). The OPS lists only a few drugs intended for reimbursement; otherwise, medication as such is excluded.

Cleared and aggregated data are freely published as Microsoft Access files under http://www.g-drg.de/. The public data cover only those patients with a normal length of stay (LOS). In principle, "normal" is defined for each DRG as ranging between one-third of the LOS arithmetic mean and the LOS arithmetic mean plus two standard deviations. One sheet of the database shows the ICD-10-GM codes together with information on the frequency as a primary and as a secondary diagnosis for each of the years 2003 to 2006. For 2007, the InEK published this sheet only for a voluntary sample of $10 \%$ of the hospitals delivering additional data from cost-unit accounting. The variables, definitions, and data-sampling procedures of the data collections between 2003 and 2006 and during 2007 were identical.

A projection of the results to the total number of inpatients in Germany for the years 2003 to 2007 is implemented assuming the representativity of both the patients with a normal LOS and the hospital sample. The total number of in-patients was drawn from further information provided by the InEK.

\section{Identification of relevant ICD-10 codes}

In the ICD-10-GM, 505 codes indicating a possible ADE were identified (cf. appendix for a list of the codes) [24]. This list extends previous work $[11,28,29]$. The identified codes were classified into seven categories, each with respect to its validity as an indicator for an ADE and its definition in the ICD-10. These categories are as follows:

- Category A.1: A drug-related causation was noted in the ICD-10, e.g., G44.4 "Drug-induced headache, not elsewhere classified."

- Category A.2: A drug- or other substance-related causation was noted in the ICD-10, e.g., I42.7 "Cardiomyopathy due to drugs and other external agents."

- Category B.1: The event was denoted as a drug poisoning, thus implying an unphysiological dosage, e.g., T36.0 "Poisoning: Penicillins."

- Category B.2: The event was denoted as poisoning by or harmful use of drugs or other substances, e.g., T50.9 "Poisoning: Other and unspecified drugs, medicaments, and biological substances."

- Category C: A drug related causation was very likely, e.g., A04.7 "Enterocolitis due to Clostridium difficile."

- Category D: A drug-related causation was likely, e.g., F52.2 "Failure of genital response." 
- Category E: A drug-related causation was possible, e. g., J81 "Pulmonary edema."

Regarding categories A.2 and B.2, other substances or measures may have caused the adverse event. The coding of categories $\mathrm{C}$ to $\mathrm{E}$ lacks an explicit reference to a medication. The German modification of the ICD-10 offers only a few codes for "Complications of medical and surgical care" (group Y40-Y84), detailed in the chapter "External causes of morbidity and mortality." In particular, there is no information on specific drugs. These codes were assigned to categories $\mathrm{A} 2$ and $\mathrm{C}$.

Due to repeated changes in the ICD-10-GM, the code list differs from year to year and the number of codes has increased from 482 (in 2003) to 505 (in 2009). In terms of content, the list has remained unaffected. The exception was in 2003, when the code for drug-induced agranulocytosis and neutropenia was not available in the ICD-10. Table 1 shows the number and percentage of codes for each of the seven categories. Over $70 \%$ of the codes (categories $\mathrm{A}$ to $\mathrm{C}$ ) indicate an $\mathrm{ADE}$ as being very likely.

\section{Drug-related hospital admissions}

After thorough examination and analysis, the diagnosis that directly led to the hospital admission was defined as the primary diagnosis, according to the German coding standards [30]. There was exactly one primary diagnosis for each hospital episode. An ADE coded as primary diagnosis was therefore always acquired before the current episode. For that reason, the results related to the primary diagnoses served as a proxy for drugrelated hospital admissions.

\section{Hospital-acquired ADE}

According to the German coding standards, every disease other than the one coded as the primary diagnosis and requiring diagnostic, therapeutic, supportive, nursing, or monitoring efforts has to be coded as a secondary diagnosis [30]. This definition therefore includes comorbidities as well as complications. A definite distinction between "prior to admission" and "acquired during hospitalization" was not possible because a "present on admission" indicator was not available [31]. However, the results related to the secondary diagnoses were used as a proxy for hospital-acquired ADEs. Between 2003 and 2006, the number of secondary diagnoses per case increased from 3.5 to 4.4 (2003: 3.5, 2004: 4.0, 2005: 4.1, 2006: 4.4, and 2007: 4.3). To control for this increase, the results for hospital-acquired ADEs were standardized based on the average number of such events in 2006, as the reference year. It should be noted that one case can simultaneously be assigned several codes from one or more of the categories A to E.

\section{Statistics}

Data from the years 2003 to 2006 represented threequarters of the target population of all in-patients in Germany, with both absolute and relative frequencies reported. To identify a trend within the categories, a linear regression was performed using the nationwide rate as the dependent variable and the year as the independent variable. Statistical significance was assumed at $\mathrm{p} \leq$ 0.05. The data were administered with Microsoft Access 2007 and analyzed with Microsoft Excel 2007 and PASW Statistics 17.0.

\section{Results}

About 48 million hospital episodes were included in this analysis of ADEs. From 2003 to 2006, the InEK sheets covered between 11,205,770 and 11,978,011 hospital episodes (Table 2), representing between $72 \%$ (2003) and $79 \%$ (2006) of all episodes recorded with the G-DRG system. The $10 \%$ sample of hospitals in 2007 consisted of $1,964,313$ episodes (13\% of all episodes in 2007). Figure 1 shows the averages of the annual ADE rates in the seven categories.

\section{Drug-related hospital admissions}

The results from the years 2003 to 2007 for the various categories are presented in Table 3. Between $0.54 \%$ and $0.67 \%$ of the episodes were assigned a primary diagnosis from categories A to C (2003: 0.54\%, 2004: 0.62\%, 2005: 0.63\%, 2006: $0.67 \%$, and 2007: 0.64\%). These episodes were very likely caused by drug-related hospital

Table 1 Distribution of ICD-10-GM codes considered indicative of an adverse drug event (ADE)

\begin{tabular}{llrr}
\hline Category & Definition & Number of codes & Proportion of all codes \\
\hline A.1 & Caused by a drug & 104 & 78 \\
A.2 & Caused by a drug or other substance & 133 & $15.4 \%$ \\
B.1 & Poisoning by drug & 15 & $26.3 \%$ \\
B.2 & Poisoning by or harmful use of a drug or other substance & 30 & $3.0 \%$ \\
C & ADE very likely & 83 & $5.9 \%$ \\
D & ADE likely & 62 & $16.4 \%$ \\
E & ADE possible & 505 & $12.3 \%$ \\
\hline Total & & $100.0 \%$ \\
\hline
\end{tabular}


Table 2 Study population

\begin{tabular}{|c|c|c|c|c|c|}
\hline & \multicolumn{5}{|c|}{ Year } \\
\hline & 2003 & 2004 & 2005 & 2006 & $2007^{\dagger}$ \\
\hline $\begin{array}{l}\text { In-patients } \\
\text { (number) }\end{array}$ & $11,912,797$ & $11,205,770$ & $11,269,412$ & $11,978,011$ & $12,244,671$ \\
\hline \multicolumn{6}{|c|}{ PCCL (percentage) } \\
\hline 0 & 56.45 & 52.25 & 52.75 & 53.64 & 55.16 \\
\hline 1 & 0.62 & 0.60 & 0.52 & 0.80 & 1.41 \\
\hline 2 & 14.73 & 15.07 & 13.83 & 13.40 & 14.35 \\
\hline 3 & 16.67 & 17.75 & 17.51 & 17.59 & 17.69 \\
\hline 4 & 11.52 & 14.33 & 15.40 & 14.56 & 11.39 \\
\hline \multicolumn{6}{|c|}{ Sex (percentage) } \\
\hline Male & 45.40 & 45.33 & 45.65 & 45.95 & 45.96 \\
\hline Female & 54.60 & 54.66 & 54.34 & 54.04 & 54.04 \\
\hline \multicolumn{6}{|c|}{ Age group (percentage) } \\
\hline$<18$ & 13.38 & 12.97 & 12.60 & 12.08 & 11.88 \\
\hline 18 to 59 & 39.43 & 37.84 & 37.44 & 36.92 & 36.62 \\
\hline 60 to 79 & 35.61 & 36.45 & 36.69 & 36.93 & 36.86 \\
\hline$>79$ & 19.84 & 21.65 & 22.41 & 23.52 & 24.13 \\
\hline \multicolumn{6}{|c|}{ Length of stay } \\
\hline $\begin{array}{l}\text { Mean } \\
\text { (days) }\end{array}$ & 7.31 & 7.51 & 7.29 & 7.35 & 7.26 \\
\hline $\begin{array}{l}\text { Stdev } \\
\text { (days) }\end{array}$ & 3.15 & 3.16 & 3.03 & 3.05 & 3.03 \\
\hline
\end{tabular}

Characteristics of in-patients with a normal length of stay. PCCL is the patient clinical complexity level, a comorbidity measure used within the G-DRGs $(0=$ no complications or comorbidities, $4=$ catastrophic complications or comorbidities). The figures published per DRG were weighted with the number of in-patients per DRG.

${ }^{\dagger}$ The study sample for 2007 included only 1,964,313 in-patients with information on diagnoses.

admission. The missing code for drug-induced agranulocytosis and neutropenia accounts for the lower rate of $0.54 \%$ in 2003 . Five percent of the admissions were at least possibly drug related (categories A-E). Over time, there was a highly significant rise in category $C$,

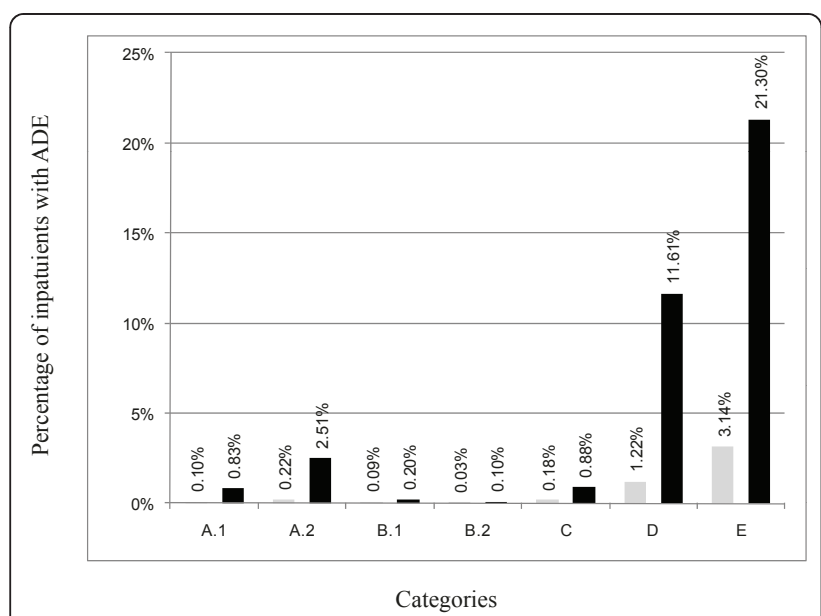

Figure 1 Average annual rates of adverse drug events (ADEs) in the seven categories (left, gray column: drug-related admissions; right, black column: hospital-acquired). implying an increase in very likely ADEs ( $p<0.001)$. Likely ADEs (category D, p = 0.029) as well as the overall rate $(\mathrm{p}=0.038)$ increased considerably; in contrast to the slight decrease in drug-induced or other intoxications (category B.2, p =0.010). There were no statistically significant changes in the remaining categories.

Among categories A to $\mathrm{C}$, the ten most frequent events in 2005 and 2006 were the same, with only a small change in their ranking (Table 4). In all other years, these diagnoses ranked among the top 20. The most frequent drug-related cause for a hospital admission was enterocolitis due to Clostridium difficile infection, responsible for almost one out of every 1000 episodes.

\section{Hospital-acquired ADE}

Between 4.46\% (in 2005) and 4.60\% (in 2006) of all episodes included a secondary diagnosis from categories AC (Table 5). These diagnosis were very likely druginduced with a suspicion for being hospital-acquired. This result represents an upper estimate because preadmission diseases were recorded as well. There was a statistically significant increase in the number of events in categories A.1 $(\mathrm{p}=0.008), \mathrm{C}(\mathrm{p}=0.022), \mathrm{D}(\mathrm{p}=$ $0.001)$, E ( $p=0.003)$, and overall ( $p<0.001)$, and a statistically significant decrease in categories A.2 ( $\mathrm{p}=$ $0.018)$, B.1 ( $\mathrm{p}=0.054)$, and B.2 ( $\mathrm{p}=0.005)$.

With minor deviations, the ten most frequent events in categories A-C in 2006 ranked among the top 20 events in other years (Table 6). The unspecific code T88.7 was the most frequent one from categories A to C in 2006 but not in 2007. In Table 6, Y57.9 is a supplementary code of the ICD-10-GM and is solely used in order to classify a disease even more precisely.

\section{Discussion}

\section{Drug-related hospital admissions}

According to German routine data from 2003 to 2007, almost $0.7 \%$ of all hospital admissions were very likely drug-related. Reasons for admission coded as a secondary diagnosis remained unconsidered. This suggests that the results represent a lower estimate. From 2003 to 2007, there was a considerable increase in diseases that were very likely ADEs and which resulted in hospital admission. The reason for this increase is not known. The proportion of in-patients 80 years and older increased continuously between 2003 and 2007. Associated with this aging population might be an increased risk of ADEs due to multimorbidity and subsequent polymedication. Among all hospital admissions, 5\% were at least possibly drug-related. Hence, a relevant number of hospital admissions in Germany can be ascribed to adverse drug reactions and medication errors. The most common ADEs remained the same over time. 
Table 3 Drug-related hospital admissions per category

\begin{tabular}{lrrrrrrrrrrr}
\hline Category & \multicolumn{2}{c}{$\mathbf{2 0 0 3}$} & \multicolumn{2}{c}{$\mathbf{2 0 0 4}$} & \multicolumn{2}{c}{$\mathbf{2 0 0 5}$} & \multicolumn{2}{c}{$\mathbf{2 0 0 6}$} & \multicolumn{2}{c}{ 2007 } \\
\hline A.1 & Rate & Number & Rate & Number & Rate & Number & Rate & Number & Rate & Number & Rate \\
A.2 & $0.06 \%$ & 9546 & $0.10 \%$ & 14728 & $0.10 \%$ & 14867 & $0.12 \%$ & 18287 & $0.11 \%$ & 17664 & $0.10 \%$ \\
B.1 & $0.22 \%$ & 36614 & $0.23 \%$ & 34894 & $0.23 \%$ & 34194 & $0.20 \%$ & 30689 & $0.20 \%$ & 31842 & $0.22 \%$ \\
B.2 & $0.08 \%$ & 13676 & $0.10 \%$ & 14958 & $0.09 \%$ & 13582 & $0.11 \%$ & 16840 & $0.07 \%$ & 10424 & $0.09 \%$ \\
C & $0.04 \%$ & 6188 & $0.03 \%$ & 5172 & $0.03 \%$ & 4823 & $0.03 \%$ & 4857 & $0.03 \%$ & 4697 & $0.03 \%$ \\
D & $0.14 \%$ & 22883 & $0.16 \%$ & 24394 & $0.18 \%$ & 27082 & $0.20 \%$ & 30699 & $0.22 \%$ & 34623 & $0.19 \%$ \\
E & $1.09 \%$ & 181152 & $1.19 \%$ & 179801 & $1.17 \%$ & 175682 & $1.24 \%$ & 187583 & $1.40 \%$ & 218105 & $1.23 \%$ \\
A - E & $2.95 \%$ & 490194 & $3.10 \%$ & 469040 & $3.16 \%$ & 474140 & $3.36 \%$ & 509535 & $3.10 \%$ & 482905 & $3.14 \%$ \\
\hline Total number of in-patients & $4.58 \%$ & 760252 & $4.91 \%$ & 742987 & $4.97 \%$ & 744369 & $5.26 \%$ & 798490 & $5.14 \%$ & 800260 & $4.98 \%$ \\
\hline
\end{tabular}

The rate is the proportion of the sample from the respective year. The absolute number of in-patients within each category is a linear extrapolation from the sample to the target population (Germany). The total rate is the weighted average for the years 2003 to 2007.

Table 4 The ten most frequent ADEs in 2006 recorded as the primary diagnosis (in descending order)

\begin{tabular}{llrr}
\hline ICD-10-GM & Category & Admissions \\
\hline Code & Text & Frequency & Percentage \\
\hline A04.7 & Enterocolitis due to Clostridium difficile & C & 9874 \\
T88.7 & Unspecified adverse effect of drug or medicament & A.2 & 5004 \\
195.2 & Hypotension due to drugs & A.1 & 3720 \\
D69.0 & Allergic purpura & $\mathrm{C}$ & 3526 \\
T50.9 & Poisoning: Other and unspecified drugs, medicaments and biological substances & 0.033 \\
T78.3 & Adverse effects, not elsewhere classified: angioneurotic edema & 0.025 \\
L27.0 & Generalized skin eruption due to drugs and medicaments & A.2 & 3501 \\
K52.1 & Toxic gastroenteritis and colitis & A.2 & 3465 \\
D70.10 & Drug-induced agranulocytosis and neutropenia: Critical phase $<10$ days & C & 3400 \\
T78.4 & Adverse effects, not elsewhere classified: allergy, unspecified & A.1 & 2727 \\
\hline Total number of in-patients & A.2 & 0.023 \\
\hline
\end{tabular}

Table 5 Hospital-acquired ADEs per category

\begin{tabular}{|c|c|c|c|c|c|c|c|c|c|c|c|}
\hline \multirow[t]{2}{*}{ Category } & \multicolumn{2}{|c|}{2003} & \multicolumn{2}{|c|}{2004} & \multicolumn{2}{|c|}{2005} & \multicolumn{2}{|c|}{2006} & \multicolumn{2}{|c|}{2007} & \multirow{2}{*}{$\begin{array}{r}\text { Total } \\
\text { Rate }\end{array}$} \\
\hline & Rate & Number & Rate & Number & Rate & Number & Rate & Number & Rate & Number & \\
\hline$\overline{A .1}$ & $0.61 \%$ & 101850 & $0.80 \%$ & 121181 & $0.84 \%$ & 126113 & $0.90 \%$ & 136963 & $1.00 \%$ & 155226 & $0.85 \%$ \\
\hline A. 2 & $2.78 \%$ & 460850 & $2.54 \%$ & 383580 & $2.48 \%$ & 371473 & $2.47 \%$ & 374988 & $2.29 \%$ & 356265 & $2.52 \%$ \\
\hline B. 1 & $0.24 \%$ & 39127 & $0.23 \%$ & 34158 & $0.21 \%$ & 31197 & $0.21 \%$ & 31816 & $0.14 \%$ & 21425 & $0.21 \%$ \\
\hline B. 2 & $0.13 \%$ & 20939 & $0.12 \%$ & 17627 & $0.10 \%$ & 15521 & $0.10 \%$ & 14712 & $0.07 \%$ & 11039 & $0.11 \%$ \\
\hline C & $0.79 \%$ & 130548 & $0.81 \%$ & 122058 & $0.83 \%$ & 124617 & $0.92 \%$ & 139172 & $1.05 \%$ & 163740 & $0.89 \%$ \\
\hline D & $9.55 \%$ & 1585917 & $10.79 \%$ & 1632913 & $11.87 \%$ & 1778861 & $12.56 \%$ & 1907125 & $13.28 \%$ & 2066457 & $11.74 \%$ \\
\hline E & $19.18 \%$ & 3184349 & $20.36 \%$ & 3080717 & $21.00 \%$ & 3148326 & $22.01 \%$ & 3342171 & $23.92 \%$ & 3721954 & $21.40 \%$ \\
\hline$A-E$ & $33.28 \%$ & 5523579 & $35.64 \%$ & 5392233 & $37.33 \%$ & 5596108 & $39.17 \%$ & 5946946 & $41.75 \%$ & 6496107 & $37.61 \%$ \\
\hline Total numb & ients & 16598546 & & 15127645 & & 14989953 & & 15181779 & & 15559359 & \\
\hline
\end{tabular}

The rate is the proportion of the sample from the respective year. The absolute number of in-patients within each category is a linear extrapolation from the sample to the target population (Germany). Rate and number are standardized for the average number of secondary diagnoses in 2006. The total rate shows the weighted average for the years 2003 to 2007. 
Table 6 The ten most frequent ADEs in 2006 recorded as secondary diagnoses (in descending order)

\begin{tabular}{|c|c|c|c|c|}
\hline \multicolumn{2}{|c|}{ ICD-10-GM } & \multirow[t]{2}{*}{ Category } & & \multirow{2}{*}{$\begin{array}{l}\text { Admissions } \\
\text { Percentage }\end{array}$} \\
\hline Code & Text & & Frequency & \\
\hline T88.7 & Unspecified adverse effect of drug or medicament & A.2 & 83182 & 0.548 \\
\hline Y57.9 & Drug or medicament, unspecified & A.2 & 48276 & 0.318 \\
\hline T78.4 & Adverse effects, not elsewhere classified: allergy, unspecified & A.2 & 42677 & 0.281 \\
\hline D69.58 & Secondary thrombocytopenia, not described as transfusion resistant & C & 31791 & 0.209 \\
\hline A04.7 & Enterocolitis due to Clostridium difficile & C & 26341 & 0.174 \\
\hline T80.1 & Vascular complications following infusion, transfusion, or therapeutic injection & A.2 & 20742 & 0.137 \\
\hline D70.10 & Drug-induced agranulocytosis and neutropenia: Critical phase $<10$ days & A.1 & 14022 & 0.092 \\
\hline D61.10 & Drug-induced aplastic anemia due to chemotherapy & A.1 & 13003 & 0.086 \\
\hline D69.59 & Secondary thrombocytopenia, not otherwise specified & C & 12357 & 0.081 \\
\hline F13.7 & $\begin{array}{l}\text { Mental and behavioral disorders due to use of sedatives or hypnotics, residual and late-onset } \\
\text { psychotic disorder }\end{array}$ & A.2 & 12153 & 0.080 \\
\hline \multicolumn{2}{|c|}{ Total number of in-patients } & & 15181779 & 100.00 \\
\hline
\end{tabular}

In a review of 25 prospective observational studies, a $5.3 \%$ rate of ADR-related admissions was estimated [4]. Waller et al. examined drug-induced hospital admissions using the Hospital Episodes Statistics database from England [21]. Their analysis showed that $0.35 \%$ of hospital admissions were coded as 'drug-induced'. The ICD10 codes considered by in that study roughly correspond to categories A.1 and C of the present work. The rate of $0.35 \%$ is in accordance with the range of 0.20 (2003, categories A.1 and C) to 0.34 (2007, categories A.1 and C) in Germany. The frequency of recorded ADRs has increased over time in both England and Germany. Waller et al., drawing conclusions from the Hospital Episodes Statistic in England, reported an increase of $40 \%$ between 1996 and 2000 [21], and Patel et al., in another study carried out in England, calculated an increase of 45\% between 1998 and 2005 [32]. In Germany, we determined an increase of $30 \%$ in drug-related admissions between 2004 and 2007 as indicated by a primary diagnosis assigned to categories A.1 and C.

\section{Hospital-acquired ADE}

According to our findings, an ADE as consequence of a hospital stay can be expected in almost $5 \%$ of hospital episodes. This percentage, however, has to be understood as an approximate upward assessment since there were no case-related data. At 5\%, drug-related ICD codes represent almost $50 \%$ of the estimated $10 \%$ of inpatients in Germany who suffer an adverse event [33].

There has been an overall increase in hospitalacquired ADEs. A documentation artifact was controlled for in the presented study by standardizing the average number of secondary diagnoses in 2006. On the one hand, the increase in the mean number of diagnoses between 2003 and 2006 can be explained by improved completeness of recording complications and comorbidities. On the other hand, there are case-mix changes, since the population has become older. However, both decreases in the length of stay and the comorbidity measure have remained stable over time (Table 2).

The rate of suspected cases in Germany is similar to the estimate of $5.3 \%$ reported by Kongkaew et al. [4]. In Western Australia, the trend of repeated in-hospital treatments due to ADR was examined between 1980 and 2003 based on the reimbursement data of patients 60 years of age and older [28]. During the entire study period, the rate was about $5.9 \%$ but the number of repeat admissions increased. The authors exclusively used supplementary codes for the identification of an ADR according to the ICD-9 and ICD-10, such as Y57.9, and took into account both pre-admission and in-hospital ADRs [28].

The literature is not always precise in differentiating between ADEs leading to admission and hospitalacquired ADEs. For example, a nationwide study from The Netherlands analyzed primary and secondary diagnoses together to assess the frequency of ADE-related hospitalizations [34]. For 2001, the rate was $1.83 \%$. Our results are similar to those from a retrospective review of clinical records published by Brennan et al. [35]. However, a meta-analysis of prospective studies yielded an estimate of $15.1 \%$, which represents a considerably higher rate of ADR episodes than determined in the present study [3]. The German Coalition for Patient Safety suggests an overall estimate of $5-10 \%$ for in-hospital adverse events [33]. Most of these events occur in a surgical context, followed by ADE and systemic factors. Adverse events in connection with other diagnostic, therapeutic, or invasive procedures are reportedly less frequent [36].

\section{Routine data}

In a few studies, only routine hospital statistics were used in the assessment of ADEs. The results are 
comparable to ours and it was consistently suggested that this database can contribute positively to health monitoring with respect to drug-related patient safety issues, although the issue of underassessment remains.

A differentiation between adverse drug reactions and medication errors as well as between comorbidities and complications is at the moment only partially accomplished by the ICD and the variables available in the data set. The application of routine data to medication safety and pharmacovigilance would therefore benefit from a further tailoring of the ICD-10. For example, the codes of categories A.2 and B.2 should be divided into those pertaining to drug-related events and those pertaining to other causes. This should be taken into account by the WHO in the 11th revision of the ICD. Furthermore, an enrichment of routine data by integrating data derived from other electronic sources related to hospital information systems might additionally enable an automatic signaling even on the level of the individual patient [37]. For example, lab results and sequences of lab results can deliver important information about ADEs. Also, the inclusion of a "present on admission" indicator could differentiate between complications and comorbidities [31]. However, from our point of view, this indicator only partially solves the underlying problem of distinguishing between the two conditions, as it is closely related to differing notions about comorbidity [38-40]. For example, an adverse event due to a medication error occurring in hospital stay A is still hospitalacquired if the patient is later admitted to hospital stay $\mathrm{B}$, but then the event is considered "present on admission." Thus, for improved patient safety and pharmacovigilance, information is needed independently of administrative events. In the above example, the date the event was recognized should be recorded by annotating the diagnosis code, thus preserving information on the course of the disease. Medications are not currently included in hospital routine data in Germany, although some codes of the ICD-10-GM cover such information, for example in group F10-F19 "Mental and behavioral disorders due to psychoactive substance use." Thus, it might be possible to similarly correlate drugs and events for specific areas.

\section{Study limitations}

The recording of an ADE requires the identification of a drug as the cause of the symptom or the disease. This identification may be difficult but it is imperative when using the specific codes of the ICD-10-GM (categories A.1, A.2, B.1, and B.2). In addition, differences in ADRdefinitions affect adversely the reliability of ADE signal systems [41,42]. A contamination of our results due to the inclusion of other causes (e.g., self-poisoning) in categories A.2 and B.2 has to be accepted, given the mix of different causes covered by a single ICD-10-code. Furthermore, since the list of variables provided by the InEK is limited, multiple counting of a single case has to be accepted.

Reliability and validity issues of administrative data may restrict the generalization of the presented results [43]. However, the coding quality of diagnoses and procedures in German hospitals has reached a standard high enough to allow the use of hospital routine data for quality management as well as health services research [44-47]. Revenue protection claims likewise require a detailed and correct documentation.

The average number of secondary diagnoses per case increased from 2003 to 2007. To exclude changes in registration habits, we standardized the rates of hospitalacquired ADEs according to their average number in 2006.

Although routine data may well be sufficient in terms of completeness of diagnoses and operative procedures, their accuracy is not confirmed. For example, in our study, ADEs present on admission were unintentionally counted as hospital-acquired if recorded as the secondary diagnosis. We expect situations such as this one to be the exception, however, and they do not invalidate the results regarding hospital-acquired ADEs.

\section{Conclusions}

The results of this study support the innovative approach of using hospital routine data to obtain health-related statistics regarding medication safety and pharmacovigilance. The analyses show an increase in drug-related admissions and hospital-acquired ADEs in Germany, in line with studies from other countries. This increase should be further evaluated in studies based on detailed data. Routine data provided by hospitals and physician offices are a reliable and valid platform for obtaining information on patient safety and are free of the cost resources incurred by data acquisition. Thus, a refinement of the ICD is recommended, as it will continue to improving both the monitoring of patient safety and pharmacovigilance. Moreover, the data can be used by Health Department/Ministry politicians, patient organizations, health insurance institutions, and pharmaceutical companies to evaluating drug safety over time, as a supplement to established methods such as spontaneous reporting systems. Restrictions occurring through the limited information available, such as the absence of data regarding medication, remain to be addressed.

\section{Appendix}

List of ICD-10-GM-codes indicating a possible ADE. Codes within each category in alphabetical order.

Category A.1: D52.1, D59.0, D59.2, D61.10, D61.18, D61.19, D69.52, D69.53, D70.10, D70.11, D70.12, 
D70.18, D70.19, E06.4, E16.0, E23.1, E24.2, E27.3, E66.10, E66.11, E66.12, E66.19, G21.0, G21.1, G24.0, G25.1, G25.4, G25.6, G44.4, G62.0, G72.0, H26.3, H40.6, I95.2, J70.2, J70.3, J70.4, K85.30, K85.31, L10.5, L43.2, L56.0, L56.1, L64.0, M10.20, M10.21, M10.22, M10.23, M10.24, M10.25, M10.26, M10.27, M10.28, M10.29, M32.0, M80.40, M80.41, M80.42, M80.43, M80.44, M80.45, M80.46, M80.47, M80.48, M80.49, M81.40, M81.41, M81.42, M81.43, M81.44, M81.45, M81.46, M81.47, M81.48, M81.49, M83.50, M83.51, M83.52, M83.53, M83.54, M83.55, M83.56, M83.57, M83.58, M83.59, M87.10, M87.11, M87.12, M87.13, M87.14, M87.15, M87.16, M87.17, M87.18, M87.19, N14.0, O74.4, P04.0, P04.1, P96.2, Q86.1, Q86.2, R50.2, T88.3

Category A.2: D64.2, E03.2, F11.0, F11.1, F11.2, F11.3, F11.4, F11.5, F11.6, F11.7, F11.8, F11.9, F13.0, F13.1, F13.2, F13.3, F13.4, F13.5, F13.6, F13.7, F13.8, F13.9, F15.0, F15.1, F15.2, F15.3, F15.4, F15.5, F15.6, F15.7, F15.8, F15.9, F19.0, F19.1, F19.2, F19.3, F19.4, F19.5, F19.6, F19.7, F19.8, F19.9, G21.2, I42.7, L23.3, L24.4, L25.1, L27.0, L27.1, L27.8, L27.9, M34.2, N14.1, N14.2, N14.3, N14.4, O35.5, P04.4, P58.4, P93, P96.1, T78.2, T78.3, T78.4, T78.8, T78.9, Т80.1, Т80.2, Т80.3, T80.4, T80.5, Т80.6, Т80.8, Т80.9, T88.6, T88.7, Y57.9, Y59.9

Category B.1: Т36.0, Т36.1, Т36.2, Т36.3, Т36.4, Т36.5, Т36.6, Т36.7, Т36.8, Т36.9, Т37.0, Т37.1, Т37.2, T37.3, Т37.4, Т37.5, Т37.8, Т37.9, Т38.0, Т38.1, Т38.2, T38.3, Т38.4, Т38.5, Т38.6, Т38.7, Т38.8, Т38.9, Т39.0, T39.1, Т39.2, Т39.3, Т39.4, Т39.8, Т39.9, Т40.0, Т40.1, T40.2, T40.3, T40.4, T40.5, T40.6, T40.7, T40.8, T40.9, T41.0, T41.1, T41.2, T41.3, T41.4, T41.5, T42.0, T42.1, T42.2, T42.3, T42.4, T42.5, T42.6, T42.7, T42.8, T43.0, T43.1, T43.2, T43.3, T43.4, T43.5, T43.6, T43.8, T43.9, T44.0, T44.1, T44.2, T44.3, T44.4, T44.5, T44.6, T44.7, T44.8, T44.9, T45.0, T45.1, T45.2, T45.3, T45.4, T45.5, T45.6, T45.7, T45.8, T45.9, T46.0, T46.1, T46.2, T46.3, T46.4, T46.5, T46.6, T46.7, T46.8, T46.9, T47.0, T47.1, T47.2, T47.3, T47.4, T47.5, T47.6, T47.7, T47.8, T47.9, T48.0, T48.1, T48.2, T48.3, T48.4, T48.5, T48.6, T48.7, T49.0, T49.1, T49.2, T49.3, T49.4, T49.5, T49.6, T49.7, T49.8, T49.9, T50.0, T50.1, T50.2, T50.4, T50.6, Т50.7

Category B.2: F55.0, F55.1, F55.2, F55.3, F55.4, F55.5, F55.6, F55.8, F55.9, T50.3, T50.5, T50.8, T50.9, T96, X49.9

Category C: A04.7, D69.0, D69.2, D69.57, D69.58, D69.59, E15, H91.0, K52.1, K71.0, K71.1, K71.2, K71.3, K71.4, K71.5, K71.6, K71.7, K71.8, K71.9, L51.0, L51.1, L51.20, L51.21, L51.8, L51.9, L56.2, N99.0, O74.2, O74.3, Y69

Category D: D62, F52.0, F52.1, F52.2, F52.3, F52.4, F52.5, F52.6, F52.7, F52.8, F52.9, H53.0, H53.1, H53.2, H53.3, H53.4, H53.5, H53.6, H53.8, H53.9, I15.81, J45.1, K25.0, K25.1, K25.2, K25.3, K25.4, K25.5, K25.6, K25.7, K25.9, К26.0, K26.1, К26.2, К26.3, К26.4, К26.5, К26.6,
K26.7, К26.9, К27.0, К27.1, К27.2, К27.3, К27.4, К27.5, K27.6, К27.7, K27.9, К28.0, К28.1, К28.2, К28.3, К28.4, K28.5, K28.6, K28.7, K28.9, K29.0, L29.0, L29.1, L29.2, L29.3, L29.8, L29.9, L50.0, N17.0, N17.1, N17.2, N17.8, N17.9, N18.0, N18.80, N18.81, N18.82, N18.83, N18.84, N18.89, N18.9, N19, O26.6, O74.6, T88.5

Category E: E86, E87.0, E87.1, E87.2, E87.3, E87.4, E87.5, E87.6, E87.7, E87.8, I26.0, I26.9, I44.0, I44.1, I44.2, I44.3, I44.4, I44.5, I44.6, I44.7, I45.8, I47.2, I61.0, I61.1, I61.2, I61.3, I61.4, I61.5, I61.6, I61.8, I61.9, I80.0, I80.1, I80.2, I80.3, I80.8, I80.9, J38.5, J45.0, J45.8, J81, K72.0, K92.2, N62, R00.1, R06.0, R06.88, R11, R17, R21, R34, R41.0, R42, R44.0, R44.1, R44.2, R44.3, R51, R55, R58, R73.9, R74.0

\section{Acknowledgements}

We thank Ms. Monika Darchinger for support in manuscript preparation and Dipl.-Stat. Marietta Rottenkolber for the analysis of the network of regional pharmacovigilance centers data in the IBE.

\section{Authors' contributions}

JS participated in the study design, carried out the data analysis, and drafted the manuscript. JH participated in the study design and supported the data analysis. Both authors read and approved the final manuscript.

\section{Competing interests}

The authors declare that they have no competing interests.

Received: 26 October 2010 Accepted: 29 May 2011

Published: 29 May 2011

\section{References}

1. Muehlberger N, Schneeweiss S, Hasford J: Adverse drug reaction monitoring - cost and benefit considerations. Part I: frequency of adverse drug reactions causing hospital admission. Pharmacoepidemiol Drug Saf 1997, 6(Suppl 3):S71-77.

2. Lazarou J, Pomeranz BH, Corey PN: Incidence of adverse drug reactions in hospitalized patients: a meta-analysis of prospective studies. JAMA 1998, 279:1200-1205.

3. Pirmohamed M, James S, Meakin S, Green C, Scott AK, Walley TJ, Farrar K, Park BK, Brickenridge AM: Adverse drug reactions as cause of admission to hospital: a prospective analysis of 18820 patients. BMJ 2004, 329:15-19.

4. Kongkaew C, Noyce PR, Ashcroft DM: Hospital admissions associated with adverse drug reactions: a systematic review of prospective observational studies. Ann Pharmacother 2008, 42:1017-1025.

5. Davies EC, Green CF, Taylor S, Williamson PR, Mottram DR, Pirmohamed M: Adverse drug reactions in hospital in-patients: a prospective analysis of 3695 patient-episodes. PLOS ONE 2009, 4:e4439.

6. Schneeweiss S, Hasford J, Göttler M, Hoffmann A, Riethling AK, Avorin J: Admissions caused by adverse drug events to internal medicine and emergency departments in hospitals: a longitudinal population-based study. Eur J Clin Pharmacol 2002, 58:285-291.

7. Goettler M, Schneeweiss S, Hasford J: Adverse drug reaction monitoring cost and benefit considerations. Part II: cost and preventability of adverse drug reactions leading to hospital admission. Pharmacoepidemiol Drug Saf 1997, 6(Suppl 3):S79-90.

8. Kohn LT, Corrigan JM, Donaldson MS, Eds: To err is human. Building a safer health system. Washington, Institute of Medicine: National Academy Press; 1999, 312

9. Bates DW, Teich JM, Lee J, Seger D, Kuperman GJ, Ma'Luf N, Boyle D, Leape $L$ : The impact of computerized physician order entry on medication error prevention. J Am Med Inform Assoc 1999, 6:313-321.

10. Kaushal R, Shojania KG, Bates DW: Effects of computerized physician order entry and clinical decision support systems on medication safety. Arch Intern Med 2003, 163:1409-1416. 
11. Kuperman GJ, Gibson RF: Computer physician order entry: benefits, costs, and issues. Ann Intern Med 2003, 139:31-39.

12. Edwards IR: The future of pharmacovigilance: a personal view. Eur J Clin Pharmacol 2008, 64:173-181.

13. Furu K, Wettermark B, Andersen M, Martikainen JE, Almarsdottir AB, Sørensen HT: The Nordic countries as a cohort for pharmacoepidemiological research. Basic Clin Pharmacol Toxicol 2010, 106:86-94.

14. Johansson S, Wallander MA, de Abajo FJ, García Rodríguez LA: Prospective drug safety monitoring using the UK primary-care General Practice Research Database: theoretical framework, feasibility analysis and extrapolation to future scenarios. Drug Saf 2010, 33:223-232.

15. Rosati K: Using electronic health information for pharmacovigilance: the promise and the pitfalls. J Health Life Sci Law 2009, 2:173-239.

16. Williams $D$, Feely J: Underreporting of adverse drug reactions: Attitudes of Irish doctors. Irish Journal of Medical Science 1999, 168:257-261.

17. Raschetti R, Morgutti M, Menniti-Ippolito F, Belisari A, Rossignoli A, Longhini P, La Guidara C: Suspected adverse drug events requiring emergency department visits or hospital admissions. European Journal of Clinical Pharmacology 1999, 54:959-963.

18. Hopf $\mathrm{Y}$, Watson M, Williams D: Adverse-drug-reaction related admissions to a hospital in Scotland. Pharmacy World \& Science 2008, 30:854-862

19. Kane R, Wellings K, Free C, Goodrich J: Uses of routine data sets in the evaluation of health promotion interventions: opportunities and limitations. Health Education 2000, 100:33-41.

20. Solberg LI, Hurley JS, Roberts MH, Nelson WW, Frost FJ, Crain AL, Gunter MJ, Young LR: Measuring patient safety in ambulatory care: potential for identifying medical group drug-drug interaction rates using claims data. Am J Manag Care 2004, 10:753-759.

21. Waller P, Shaw M, Ho D, Shakir S, Ebrahim S: Hospital admissions for 'drug-induced' disorders in England: a study using the Hospital Episodes Statistics (HES) database. British Journal of Clinical Pharmacology 2004, 59:213-219.

22. Wu TY, Jen MH, Bottle A, Molokhia M, Aylin P, Bell D, Majeed A: Ten-year trends in hospital admissions for adverse drug reactions in England 1999-2009. J R Soc Med 2010, 103:239-250.

23. Hougland P, Nebeker J, Pickard S, Van Tuinen M, Masheter C, Elder S, Williams S, Xu W: Using ICD-9-CM codes in hospital claims data to detect adverse events in patient safety surveillance. In Advances in patient safety: new directions and alternative approaches (Vol 1: Assessment). Edited by: Battles JB, Keyes MA, Grady ML. Rockville (MD): Agency for Healthcare Research and Quality; 2008.

24. Stausberg J, Hasford J: Identification of adverse drug events: the use of ICD-10 coded diagnoses in routine hospital data. Dtsch Arztebl Int 2010, 107:23-29.

25. Bates DW, Cullen DJ, Laird N, Petersen LA, Small SD, Servi D, Laffel S, Sweitzer BJ, Seha BF, Hallisey R, van der Vliet M, Nemeskal R, Leape LL, for the ADE Prevention Study Group: Incidence of adverse drug events and potential adverse drug events. Implications for prevention. JAMA 1995, 274:29-34.

26. Morimoto T, Gandhi TK, Seger AC, Hsieh TC, Bates DW: Adverse drug events and medication errors: detection and classification methods. Qual Saf Health Care 2004, 13:306-314.

27. WHO: International drug monitoring: the role of national centers. Technical Report Series No 498 Geneva: World Health Organisation; 1972.

28. Zhang M, Holman CDAJ, Preen DB, Brameld K: Repeat adverse drug reactions causing hospitalization in older Australians: a populationbased longitudinal study 1980-2003. Br I Clin Pharmacol 2006, 63:163-170.

29. Nebeker JR, Yarnold PR, Soltysik RC, Sauer BC, Sims S, Samore MH, Rupper RW, Swanson KM, Saritz LA, Shingle J, Wu X: Developing indicators of inpatient drug events through nonlinear analysis using administrative data. Medical Care 2007, 45:81-88.

30. Deutsche Krankenhausgesellschaft, Spitzenverbände der Krankenkassen, Verband der privaten Krankenversicherung, Institut für das Entgeltsystem im Krankenhaus: Allgemeine und Spezielle Kodierrichtlinien für die Verschlüsselung von Krankheiten und Prozeduren, Version 2006. Institut für das Entgeltsystem im Krankenhaus 2005, [General and special standards for coding of diseases and procedures, version 2006].

31. Houchens RL, Elixhauser A, Romano PS: How often are potential patient safety events present on admission? The Joint Commission Journal on Quality and Patient Safety 2008, 34:154-163.
32. Patel H, Bell D, Molokhia M, Srishanmuganathan J, Patel M, Car J, Majeed A: Trends in hospital admissions for adverse drug reactions in England: analysis of national episode statistics 1998-2005. BMC Clinical Pharmacology 2007, 7:9.

33. Aktionsbündnis Patientensicherheit, Hrsg: Agenda Patientensicherheit 2007. 2007, Witten [Agenda Patient Safety 2007].

34. van der Hooft CS, Sturkenboom MC, van Grootheest K, Kingma HJ, Stricker BH: Adverse drug reaction-related hospitalizations: a nationwide study in The Netherlands. Drug Safety 2006, 29:161-168.

35. Brennan TA, Leape LL, Laird NM, Hebert L, Localio AR, Lawthers AG, Newhouse JP, Weiler PC, Hiatt HH: Incidence of adverse events and negligence in hospitalized patients. Results of the Harvard Medical Practice Study I. NEJM 1991, 324:370-376.

36. Agenda Patientensicherheit 2008. Edited by: Schrappe M, Lessing C Schmitz A, Conen D, Hart D, Hoppe-Tichy T, Jonitz G, Lauterberg J, Leppin G, Lichte T, Loskillet H 2008, Witten [Agenda Patient Safety 2008].

37. Classen DC, Pestotnik SL, Evans RS, Burke JP: Computerized surveillance of adverse drug events in hospital patients. JAMA 1991, 266:2847-2851.

38. Feinstein AR: The pre-therapeutic classification of co-morbidity in chronic disease. J Chron Dis 1970, 23:455-468

39. Pompei $\mathrm{P}$, Charlson ME, Ales K, MacKenzie CR, Norton M: Relating patient characteristics at the time of admission to outcomes of hospitalization. J Clin Epidemiol 1991, 44:1063-1069.

40. Valderas JM, Starfield B, Sibbald B, Salisbury C, Roland M: Defining comorbidity: implications for understanding health and health services. Ann Fam Med 2009, 7:357-363.

41. Edwards IR, Aronson JK: Adverse drug reactions: definitions, diagnoses, and management. Lancet 2000, 356:1255-1259.

42. Field TS, Gurwitz JH, Harrold LR, Rothschild JK, Debellis K, Seger AC, Fish LS, Garber L, Kelleher M, Bates DW: Strategies for detecting adverse drug events among older persons in the ambulatory setting. J Am Med Inform Assoc 2004, 11:492-498.

43. Iezzoni LI: Assessing quality using administrative data. Annals of Internal Medicine 1997, 127:666-674.

44. Klaus B, Ritter A, Große Hülsewiesche H, Beyrle B, Euler HU, Fender H, Hübner M, von Mittelstaedt G: Study of the quality of codification of diagnoses and procedures under DRG conditions [in German]. Gesundheitswesen 2005, 67:9-19.

45. Stausberg J, Azaouagh A: Frequency of hospital-acquired pneumonia in electronic and paper-based patient record. In eHealth: Beyond the Horizon - Get IT There - Proceedings of MIE2008 - The XXIst International Congress of the European Federation for Medical Informatics. Edited by: Andersen SK, Klein GO, Schulz S, Aarts J, Mazzolenie MC. Amsterdam: IOS Press; 2008:470-483.

46. Stausberg J, Kröger K, Maier I, Niebel W, Schneider S: Frequency of decubitus ulcer in patients of a university medical center. Combination of routine documentation and cross-sectional study [in German]. DMW 2005, 130:2311-2315.

47. Stausberg J: Quality of coding in acute inpatient care [in German]. Bundesgesundheitsbl Gesundheitsforsch Gesundheitsschutz 2007, 50:1039-1046.

\section{Pre-publication history}

The pre-publication history for this paper can be accessed here: http://www.biomedcentral.com/1472-6963/11/134/prepub

\section{doi:10.1186/1472-6963-11-134}

Cite this article as: Stausberg and Hasford: Drug-related admissions and hospital-acquired adverse drug events in Germany: a longitudinal analysis from 2003 to 2007 of ICD-10-coded routine data. BMC Health Services Research 2011 11:134. 